\title{
Prenatal diagnosis and presymptomatic detection of neurofibromatosis type 1
}

\author{
M Upadhyaya, A Fryer, J MacMillan, W Broadhead, S M Huson, P S Harper
}

\begin{abstract}
A two year experience of DNA diagnosis for NF1 is presented. Twenty-three NF1 families have been analysed using 11 closely linked and intragenic markers. Prenatal testing was undertaken for six families; 11 affected subjects and their partners wished to know if they would be informative for future prenatal testing, seven of whom are so far fully informative. Presymptomatic testing was done for six subjects. Despite the availability of a series of closely linked markers, informativeness could not be achieved in all of the families tested.
\end{abstract}

Neurofibromatosis type 1 (NF1) is an autosomal dominant condition, affecting around 1 in 3000 subjects. The disease is typically characterised by café au lait spots, neurofibromas, and Lisch nodules. The main problems in NF1 arise secondary to disease complications, which are extremely variable and the occurrence cannot be predicted even within families. ${ }^{12}$ The gene for NF1 was mapped to chromosome 17 in $1987^{34}$ and several close flanking markers were defined subsequently. ${ }^{56}$ Balanced translocations involving chromosome band 17q11.2 were reported in two unrelated NF1 patients ${ }^{78}$; the breakpoints on chromosome 17 were $60 \mathrm{~kb}$ apart. ${ }^{9}$ Positional cloning (reverse genetic) techniques have enabled the gene to be cloned. ${ }^{10}{ }^{11}$ Using a RNA PCR based assay, ${ }^{10}$ it was confirmed that translocations prevented transcription of the NF1 gene on the affected chromosome 17 and NF1 cDNAs were interrupted by both translocation breakpoints. ${ }^{1112}$ The NF1 gene has been reported to be interrupted by four deletions, $11 \mathrm{~kb}, 40 \mathrm{~kb}, 160 \mathrm{~kb}$, and $90 \mathrm{~kb},{ }^{113}$ one insertion, ${ }^{10}$ and three point mutations. ${ }^{14}$ Such specific changes are so far too infrequent to be of clinical application outside these rare specific families.

With the availability of closely linked and intragenic markers, it has been possible to provide prenatal and heterozygote testing for NF1. We report here our experience over a two year period of providing a diagnostic service for NF1 using DNA markers.

\section{Material and methods}

The families used in the analysis were referred from clinical genetics centres in Britain and elsewhere in Europe. Blood for DNA samples, clinical data, and pedigree data were provided by the referring centre after full discussion with us. Chorionic villus tissue or DNA were sent by courier.

Whole blood for DNA extraction was collected in EDTA tubes. The DNA was digested with appropriate restriction enzymes $(M s p \mathrm{I}$, RsaI, EcoRI, PstI, BamHI, HindIII, BglII, TaqI) and fractionated on 0.7 to $0.8 \%$ agarose gel before transfer by Southern blotting to Hybond N (Amersham) filters. DNA probes were labelled with ${ }^{32} \mathrm{P}$ using the primer extension method ${ }^{15}$ and hybridised to filters at $65^{\circ} \mathrm{C}$. The posthybridisation wash was in $2 \times$ SSC, $0 \cdot 1 \%$ SDS; the stringency of washing was increased as necessary. The hybridised membrane was exposed to $x$ ray film at $-70^{\circ}$ for between one and seven days.

Clinical requests were of three types: prenatal diagnosis in a continuing pregnancy, suitability for future prenatal diagnosis, and assignment of genotype in clinically normal subjects at risk.

Two point linkage analysis for risk estimation was done using the program MLINK. Allele frequencies were determined for the founder of each NF1 family and the spouses. The recombination fraction and lod scores between the NF1 locus and each marker used for the risk assessment are summarised in table 1 .

\section{Results}

Twenty-three families were referred for analysis. Prenatal testing was undertaken for six families (table 2), four giving a low risk result and two a high risk; one of these pregnancies was terminated. Eleven affected subjects and their partners wished to know if they would be informative for future prenatal diagnosis, seven of whom are so far fully informative (table 3). Presymptomatic testing was done for six subjects (table 4), this being discussed more fully below.

Particular examples are discussed here and are illustrated in the figure.

\section{CASE 1}

Th.e proband (NF 501.3), whose mother was affected, initially wanted to know whether she would be informative for future prenatal testing. Analysis of this family with markers EW206, HHH202, $\beta 8.2$, and C11.7 did not at this stage give an informative situation. By the time a pregnancy ensued, the availability of additional markers meant that the couple were informative using DNA markers VAW212 and pTH17.19. DNA analysis on a chorionic villus biopsy indicated that the fetus had inherited the grandpaternal (normal) allele and the risk 
Table 1 Chromosome 17 DNA markers used for genetic prediction in NF1.

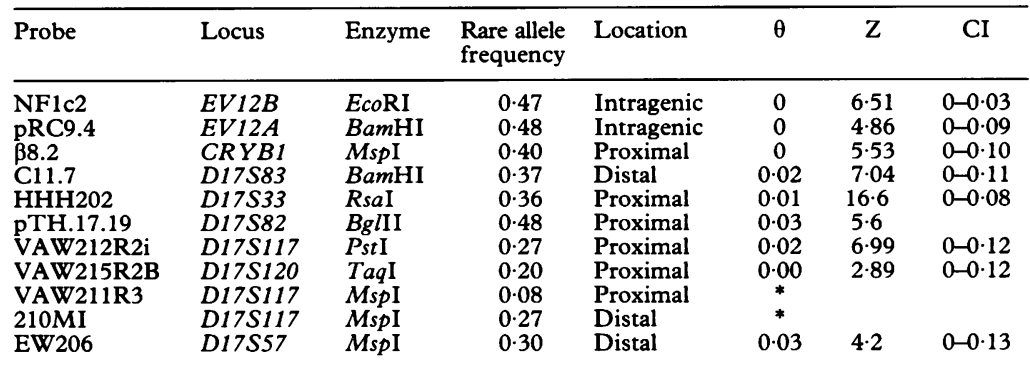

* Closely linked (D Barker, personal communication).
CASE 3

This family (NF 506) was referred to us from Finland at 10 weeks' gestation (Dr M Ryynanen). The couple was informative using flanking DNA markers $\mathrm{HHH} 202$, proximal to the disease locus, and C11.7, a distal marker. Chorion villus biopsy was obtained at 12 weeks and the fetus had inherited the high risk allele. It should be noted that it is a phase unknown situation and a recombination has taken place between $\mathrm{C} 11.7$ and the disease. The risk was calculated allowing for uncertainty of phase. The parents decided after counselling to continue the pregnancy and a female child with multiple café au lait spots was born.

Table 2 Results of requests for prenatal diagnosis in NF1.

\begin{tabular}{lllll}
\hline Case & Family & \multicolumn{1}{c}{ Probe } & \multicolumn{1}{c}{ Result } & \multicolumn{1}{c}{ Outcome } \\
\hline 1 & NF 501 & VAW212R2i & Low risk (3\%) & Continuation of pregnancy \\
2 & NF 502 & $\beta 8.2$ & Low risk $(2 \%)$ & Continuation of pregnancy \\
3 & NF 506 & HHH202 & High risk $(96 \%)$ & Continuation of pregnancy \\
4 & NF 507 & VAW212R2i & Low risk (3\%) & Continuation of pregnancy* \\
5 & NF 511 & pRC9.4 & High risk (99\%) & Termination of pregnancy \\
6 & NF 521 & 210MI & Low risk (3\%) & Continuation of pregnancy \\
\hline
\end{tabular}

* A twin pregnancy (single placenta) was diagnosed at 18 weeks' gestation and went to term. + The pregnancy was terminated before the typing result was available as the karyotype showed a 45, X (Turner) fetus.
Table 3 Requests for suitability for future prenatal diagnosis in NF1.

\begin{tabular}{lr}
\hline Result & No \\
\hline Couple fully informative & 7 \\
Couple partially $(50 \%)$ informative & 1 \\
Couple uninformative at present & 3 \\
Total requests & 11
\end{tabular}

Table 4 Results of requests for assignment of genotype status in NF1.

\begin{tabular}{llll}
\hline Case & Family & Age (y) & Result \\
\hline 1 & NF 519 & Fetus* & Unaffected \\
2 & NF 514 & 1 & Unaffected \\
3 & NF 522 & 3 & Awaited \\
4 & NF 503 & 14 & Unaffected \\
5 & NF 510 & 16 & Unaffected \\
6 & NF 523 & 16 & Unaffected \\
\hline
\end{tabular}

* Amniocentesis for maternal age; subsequently requested status in the third trimester.

to the pregnancy was reduced from $50 \%$ to $4 \%$. A healthy son has since been born.

CASE 2

The proband (NF 502.3) wished to know whether she would be informative for future prenatal testing. The family was analysed initially using closely linked markers and also with distant markers so that haplotypes could be constructed. The couple were partially informative for future prenatal diagnosis using probe $\beta$ 8.2. The couple were counselled on the significance of these DNA results and in a subsequent pregnancy they opted to have prenatal diagnosis; the risk to the fetus was reduced from $50 \%$ to $4 \%$.

\section{CASE 4}

This family (NF 507), referred by Dr E Thompson, was analysed using six DNA markers and not found to be informative. The proband (NF 507.2) presented at 8 weeks' gestation requesting prenatal diagnosis. She was found to be informative using DNA marker VAW212 and the fetus sampled carried the low risk allele. Ultrasound scan at 18 weeks' gestation unexpectedly showed a twin pregnancy with single placenta. The pregnancy continued to term with the birth of healthy twins. No further DNA studies have been undertaken on these infants.

CASE 5

This pregnancy was referred at 8 weeks' gestation from Israel (Dr J Zlotogora); the proband (NF 511.2) was considered to be a new mutation. Her clinical features included café au lait spots and neurofibromas. She had an affected son who had café au lait spots only. The couple requested prenatal diagnosis and were informative using intragenic marker pRC9.4. Chorion biopsy was taken at 12 weeks and DNA was sent in ethanol. The genotype of the fetus was the same as that of the affected sib giving a risk approaching $100 \%$. The pregnancy was terminated before the DNA result was available because the karyotype showed a $45, \mathrm{X}$ (Turner) fetus.

CASE 6

In this family, the proband (NF 513.4) had an affected father and unaffected daughter. Because of the lack of availability of prenatal diagnosis, her husband had had a vasectomy in the past. If informative for prenatal diagnosis the husband was going to have a reversal of sterilisation. This family has been analysed using 10 DNA markers, but an informative situation could not be reached.

CASE 7

This family (NF 519, table 4) was referred for DNA analysis during the first trimester of pregnancy. The DNA analysis was done rapidly and showed that the couple were suitable for prenatal diagnosis using an intragenic 

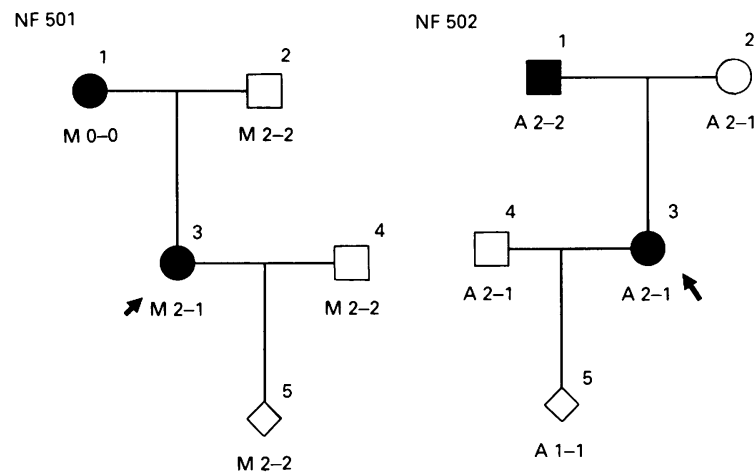

NF 506

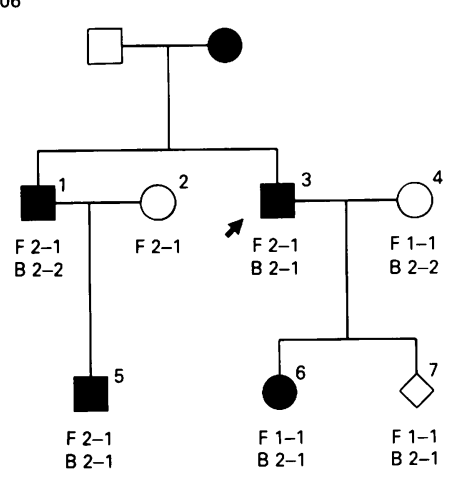

NF 511
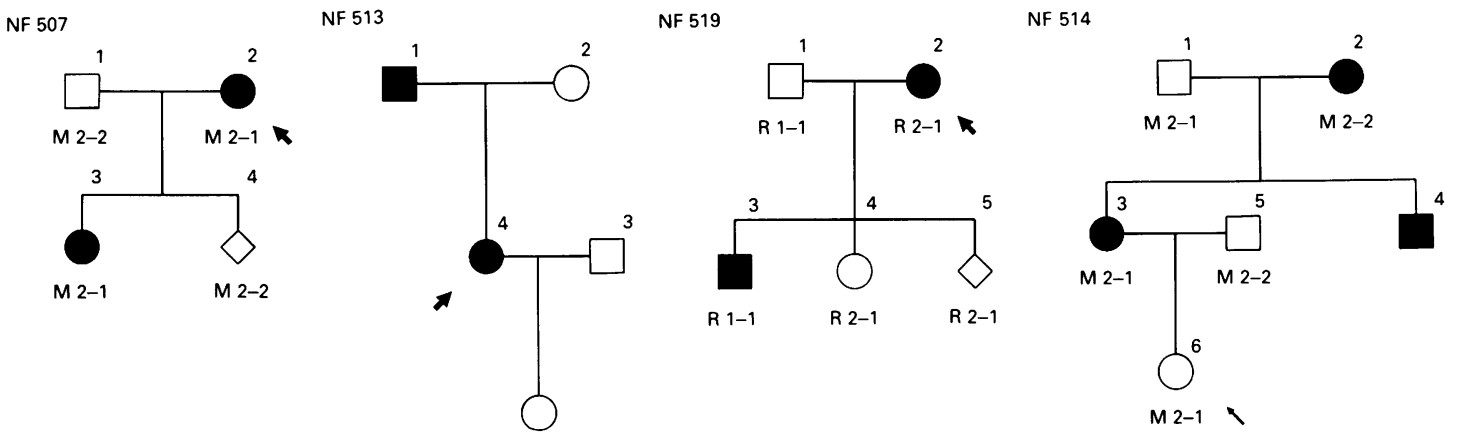

Family pedigrees. $A, \beta 8.2$ (CRYB1). B, C11.7 (D17S83). F, HHH202 (D17S33). M, VAW212R2i (D17S117). N, pRC9.4 (EV12A). $R, N F 1 c 2(E V 12 B)$.

probe. They decided against prenatal diagnosis but a subsequent amniocentesis was carried out because of advanced maternal age and DNA from amniocytes was banked. Presymptomatic testing of the banked fetal DNA was done in the third trimester at the family's request because of excessive anxiety of the mother. The fetus carried the low risk allele. A healthy son has since been born.

CASE 8

In this family, the mother (NF 514.3, table 4) had NF1 with secondary complications of severe kyphoscoliosis and seizures. The parents wanted to know the genetic status of their 15 month old daughter who did not have any signs of NF1. The couple were informative using DNA marker VAW212 and the risk of the daughter having the disease was reduced from $50 \%$ to $4 \%$.

\section{Discussion}

In undertaking linkage studies for $\mathrm{NF} 1$, we were aware that the first likely application of linked DNA markers would be for prenatal testing. In Cardiff, where a NF clinic was set up in 1987 offering annual follow up and information concerning future prenatal diagnosis, the application of the linkage approach has been found to be useful for prenatal and presymptomatic diagnosis in affected families. As with any dominant condition, at least two affected subjects were ideally needed in separate generations so that the haplotype associated with NF1 could be determined. Despite the availability of a battery of closely linked and intragenic markers, informativeness could not be achieved in all the families tested, as shown by family NF 513 . The inadequate structure of some families and lack of heterozygosity remain problems. RFLPs associated with the cDNAs for NF1 may improve this situation. ${ }^{16}$ The intragenic recombination for NF1 is not known.

The clinical criteria for the diagnosis of NF1 patients have been defined in relation to other forms of $\mathrm{NF}^{17}$ and are important to establish before tests are offered. As penetrance is almost $100 \%$ by the age of 5 years, ${ }^{18}$ clinical diagnosis after this age is not a problem; molecular testing should not be needed for clinically unaffected adults. Despite the absence of any abnormal clinical features in the adolescents included in this study, the parents still wanted the reassurance that a low risk DNA result would provide. However, in many paediatric situations, a sufficiently precise diagnosis may not be possible and knowledge of the child's genotype may be helpful. The analysis of DNA samples from asymptomatic children at $50 \%$ prior risk of inheriting the gene for NF1 is, however, a contentious issue, as is the general topic of testing children for genetic disorders, especially those of later onset. ${ }^{19}$ Some clinicians feel that it is important to make the diagnosis early so that parents can be offered counselling and guidance and that children can be followed for such complications as optic glioma and hypertension. Families which have experienced severe manifestations in a previous child may be especially concerned; the reassurance brought by the prediction of an unaffected genotype in a younger sib must be weighed against any perceived harm that an 'affected' assignment might bring in an asymptomatic child. We believe that each 
family situation is different and each request should be discussed fully with the family. The results of DNA studies should always be combined with clinical examination in order to reduce errors in the assignment of genetic status.

One study involving presymptomatic detection and informativeness for prenatal testing in NF1 has already been reported. ${ }^{20}$ The results reported in our paper are the first to include prenatal diagnosis. We have found the demand for prenatal diagnosis to be limited. In addition to the six pregnancies described here, two families were referred for analysis during pregnancy, were informative for DNA markers, but decided against prenatal testing. The main reason for not choosing to have prenatal testing in the majority of cases was that the parents would only want to consider a test which would predict disease severity. Our series also shows that it cannot be guaranteed that all couples will be informative for prenatal diagnosis, even with available closely linked markers. In addition it is preferable to perform DNA informativeness analysis before a pregnancy is undertaken. The observed outcome of the completed pregnancies have not shown any error, but since the disease is not fully penetrant until the age of 5 the final outcome is still awaited. However, in family NF 506, where DNA analysis predicted a high risk pregnancy, a female child with multiple café au lait spots was born.

Direct analysis of specific mutations or deletions is currently possible for only a very small proportion of families with NF1, but this is likely to change rapidly as the detailed structure of this large gene becomes better understood. The detection of specific mutations will permit specific prenatal diagnosis independent of family structure and will be of particular help for the large numbers of isolated cases. Mutation analysis will also establish whether cases of NF1 with unusual phenotype are indeed determined by the same locus and will thus allow genetic testing to be undertaken for these families.

We thank Drs F Collins, P O'Connell, and D Barker for the DNA probes and Dr M Sarfarazi for linkage analysis. We are grateful to
Action Research for the Crippled Child for financial support and the British Neurofibromatosis Association (LINK) for their help. We also thank the clinicians and laboratories who referred samples, in particular our colleagues in the West of Britain Molecular Genetics Consortium.

1 Riccardi VM, Eichner JE. Neurofibromatosis: phenotype, natural history and pathogenesis. Baltimore: Johns Hopkins University Press, 1986.

2 Huson SM, Compston DAS, Harper PS. A genetic study of von Recklinghausen neurofibromatosis in south-east Wales. II. Guidelines for genetic counselling. $\mathcal{f} \mathrm{Med}$ Genet 1989;26:712-21.

3 Barker D, Wright E, Nguyen K, et al. Gene for von Recklinghausen neurofibromatosis in the pericentromeric region of chromosome 17. Science 1987;236:1100-2.

4 Seizinger BR, Rouleau GA, Ozelius LJ, et al. Genetic linkage of von Recklinghausen neurofibromatosis to the nerve growth receptor gene. Cell 1987;49:589-94.

5 Upadhyaya M, Sarfarazi M, Huson S, et al. Close flanking markers for neurofibromatosis type 1 (NF1). Am $\mathcal{f}$ Hum Genet 1989;44:20-4.

6 Golgar D, Green P, Parry DM. Multipoint linkage analysis in neurofibromatosis type 1: an international collaborain neurofibromatosis type 1: an interna
tion. Am $₹$ Hum Genet 1989;44:6-12.

7 Schmidt MA, Michels VV, Dewald GW. Cases of neurofibromatosis with rearrangements of chromosome 17 fibromatosis with rearrangements of chromosome 17
involving band 17q11.2. Am $₹$ Hum Genet 1987;28:771-7.

8 Ledbetter DH, Rich DC, O'Connell P, et al. Precise localisation of NF1 to $17 \mathrm{q} 11.2$ by balanced translocation. $A m \mathcal{F}$ sation of NF1 to 17q11.2
Hum Genet 1989;44:20-4.

9 O'Connell P, Viskochil D, Buchberg AM, et al. The human homolog of EV1.2 lies between two von Recklinghausen neurofibromatosis translocations. Genomics 1990; 7:547-54.

10 Wallace M, Marchuk DA, Andersen B, et al. Type 1 neurofibromatosis gene: identification of a large transcrip disrupted in three NF1 patients. Science 1990;249:181-6.

11 Viskochil D, Buchberg AM, Xu G, et al. Deletions and a translocation interrupt a cloned gene at the neurofibromatosis type 1 locus. Cell 1990;62:187-92.

12 Xu G, O'Connell P, Viskochil D, et al. The neurofibromatosis type 1 gene encodes a protein related to GAP. Cell 10sis type 1 gene

13 Upadhyaya M, Cherryson A, Broadhead W, et al. A $90 \mathrm{~kb}$ DNA deletion associated with neurofibromatosis type $1 . \mathcal{F}$ Med Genet 1990;27:738-41.

14 Cawthon RM, Weiss R, Xu G, et al. A major segment of the neurofibromatosis type 1 gene: cDNA sequence, genomic structure, and point mutations. Cell 1990;62:193-201.

15 Feinberg AP, Vogelstein B. A technique for radiolabelling DNA restriction endonuclease fragments to high specific activities. Anal Biochem 1983;132:6-13.

16 Andersen LB, Wallace MR, Marchuk DA, et al. A polymorphic cDNA probe in the NF1 gene. Nucleic Acids Res 1991;19:197.

17 Stumpf D, Alksne A, Annegers JF, et al. Neurofibromatosis and 'NIH Consensus Development Conference Statement'. Washington, DC: US Government Printin > Office, 1987: No 12.

18 Huson SM, Compston DAS, Clarke P, et al. A genetic study of von Recklinghausen neurofibromatosis in southeast Wales. Prevalence, fitness, mutation rate, and effect east Wales. Prevalence, fitness, mutation rate, and effect of parental transm

19 Harper PS, Clarke A. Should we test children for 'adult' genetic diseases? Lancet 1990;335:1205-6.

20 Ward K, O'Connell P, Carey JC. Diagnosis of neurofibromatosis by using tightly linked, flanking DNA markers. Am f Hum Genet 1990;46:943-9. 